\title{
Inhibitory Abilities of Bacillus Isolates and Their Culture Filtrates against the Gray Mold Caused by Botrytis cinerea on Postharvest Fruit
}

\author{
Xiaomeng Chen ${ }^{\dagger}$, Yajie Wang ${ }^{\dagger}$ Yu Gao, Tongguo Gao, and Dongdong Zhang* \\ College of Life Science, Hebei Agricultural University, Baoding 071001, China \\ (Received on March 25, 2019; Revised on July 10, 2019; Accepted on July 18, 2019)
}

Botrytis cinerea, a major phytopathogenic fungus, has been reported to infect more than 200 crop species worldwide, and it causes massive losses in yield. The aim of this study was to evaluate the inhibitory abilities and effects of Bacillus amyloliquefaciens RS-25, Bacillus licheniformis MG-4, Bacillus subtilis Z-14, and Bacillus subtilis Pnf-4 and their culture filtrates and extracts against the gray mold caused by $B$. cinerea on postharvest tomato, strawberry, and grapefruit. The results revealed that the cells of $\mathrm{Z}-14$, culture filtrate of RS25 , and cells of $\mathrm{Z}-14$ showed the strongest biocontrol activity against the gray mold on the strawberry, grape, and tomato fruit, respectively. All the strains produced volatile organic compounds (VOCs), and the VOCs of Pnf-4 displayed the highest inhibition values. Based on headspace solid-phase microextraction in combination with gas chromatography-mass spectrometry, esters accounted for the largest percentage of the VOCs produced by RS-25, MG-4, Z-14, and Pnf-4 (36.80\%, $29.58 \%, 30.78 \%$, and $36.26 \%$, respectively). All the strains showed potent cellulase and protease activities, but no chitinase activity. RS-25, Z-14, and MG-4, but not Pnf-4, grew on chrome azurol $S$ agar, and an orange halo was formed around the colonies. All the strains showed biofilm formation, fruit colonization, and lipopeptide production, which may be the main modes of action of the antagonists against $B$. cinerea on the fruit. This study provides the basis for developing

\footnotetext{
${ }^{\dagger}$ These authors contributed equally to this work.

*Corresponding author.

Phone) +86-3127528273, FAX) +86-3127528273

E-mail) zhangdongcumt $@ 163 . c 0 m$

(c) This is an Open Access article distributed under the terms of the Creative Commons Attribution Non-Commercial License (http:// creativecommons.org/licenses/by-nc/4.0) which permits unrestricted noncommercial use, distribution, and reproduction in any medium, provided the original work is properly cited.
}

Articles can be freely viewed online at www.ppjonline.org. natural biocontrol agents against the gray mold caused by $B$. cinerea on postharvest fruit.

Keywords : Bacillus isolate, Botrytis cinerea, gray mold, inhibitory ability, postharvest fruit

Handling Editor : Kim, Hun

Botrytis cinerea is a major phytopathogenic and necrotrophic fungus that causes the gray mold disease (Fekete et al., 2012). The fungus has been reported to infect more than 200 crop species worldwide, such as grapes, stone fruit, berries, and vegetables, and the losses in yield before and after harvest are extensive (Williamson et al., 2007). B. cinerea is not host-specific, and its virulence varies in different plant hosts (Derckel et al., 1999; Mirzaei et al., 2009). Because it has a broad host spectrum and causes significant economic losses, $B$. cinerea has been considered as the second most important fungal pathogen worldwide (Dean et al., 2012).

In particular, postharvest losses due to fungal infections are more important for highly perishable fresh fruit than for field crops. Generally, postharvest losses are attributed to pathological decomposition due to fungal and bacterial infections; pathophysiological damage during storage due to excessive cooling or lighting or abnormalities in the atmospheric gaseous components; and physical damage, such as mechanical damage (Schnaubelt, 2005).

Synthetic fungicides are commonly used to protect crops, especially fruit, in the postharvest period. However, effective and safe non-fungicides are urgently required to control postharvest pathogens because synthetic fungicide residues are toxic to humans and the environment (Conway et al., 2005; Droby, 2006; Soylu et al., 2010). Therefore, researchers worldwide are trying to develop safe, natural, and biodegradable alternatives to replace synthetic fungicides (Grzegorczyk et al., 2017; Nalinia and Parthasarathi, 
2014).

Previous studies have confirmed the efficacy of biocontrol agents against several postharvest phytopathogenic fungi, such as species that belong to the genera Botrytis, Penicillium, and Monilinia (Bautista-Rosales et al., 2013; Mari et al., 2012; Parafati et al., 2015; Platania et al., 2012). Species that belong to the genus Bacillus can form endospores, which ensures the feasibility of commercial products with low storage requirements but a long shelf life (Posada et al., 2016). Thus, Bacillus strains can colonize the surface or wounds of postharvest fruit and produce broad-spectrum antibiotics that suppress a variety of plant pathogens (Stein, 2005). Bacillus subtilis V26 displays high antifungal activity against several fungi, including $B$. cinerea, and has powerful chitosanase activity (Kilani-Feki et al., 2016). Bacillus atrophaeus CAB-1 displays high inhibitory activity against various fungal pathogens and suppresses cucumber powdery mildew and tomato gray mold. All the compounds extracted from CAB-1 (e.g., C15-C17 fengycin A, a protein, and volatile compounds) also effectively prevented the occurrence of the cucumber powdery mildew caused by Sphaerotheca fuliginea under greenhouse conditions (Zhang et al., 2013). Bacillus cereus S42 screened from Nicotiana glauca plants native to the Tunisian Centre-East demonstrated a strong ability to suppress tomato Fusarium wilt caused by Fusarium oxysporum f. sp. lycopersici and showed proteolytic and chitinolytic activities (Abdallah et al., 2016).

In this study, we have reported the efficacy of four antagonists or their culture filtrates in controlling the gray mold caused by $B$. cinerea on postharvest fruit and discussed their ability to colonize the wounds on the fruit and synthesize antifungal metabolites.

\section{Materials and Methods}

Growth of bacterial isolates and production of culture filtrates. Bacterial isolate RS-25 from jujube fruit, MG-4 from strawberry fruit, Z-14 from wheat rhizosphere soil and Pnf-4 from wheat plant significantly inhibited the growth of various phytopathogenic fungi and were maintained at $4^{\circ} \mathrm{C}$ on streak-inoculating nutritive agar (NA) slants (Zhang et al., 2017a, 2017b). The strains were cultured overnight at $37^{\circ} \mathrm{C}$ on NA slants, transferred to Erlenmeyer flasks containing $50 \mathrm{ml}$ of the seed culture medium, and shaken at $220 \mathrm{rpm}$ for $48 \mathrm{~h}$ at $37^{\circ} \mathrm{C}$. The vegetative cells and supernatant were obtained after centrifugation at $10,000 \times g$ for $15 \mathrm{~min}$. The cells were suspended in sterile distilled water (SDW) and adjusted to the appropriate concentration $(1 \times$ $10^{8}$ cells $\left./ \mathrm{ml}\right)$, and the supernatant was filtered through a $0.22-\mu \mathrm{m}$ syringe to obtain the culture filtrate.

Antifungal activities of the Bacillus isolates and their culture filtrates against $B$. cinerea. Using the dual-culture in vitro assay described by Kilani-Feki et al. (2016), the antifungal activities of the four isolates against $B$. cinerea were evaluated. A single 5-mm-diameter mycelial disc of the test fungus was placed at the center of potato dextrose agar (PDA) plates. The samples were treated with the bacterial isolates at four symmetrical sites, a distance of $3 \mathrm{~cm}$ from the center of the plate, and then allowed to grow for 5 days at $27^{\circ} \mathrm{C}$ in darkness. The antifungal activity of the culture filtrate was measured using a diffusion plate assay modified from that described by Pretorius et al. (2015). Four evenly spaced wells ( $7 \mathrm{~mm}$ in diameter) were made $2.5 \mathrm{~cm}$ from the center of PDA plates containing $40 \mu \mathrm{g} / \mathrm{ml}$ of streptomycin sulfate. A plug of $B$. cinerea was placed at the center of the plate, and an aliquot $(50 \mu \mathrm{l})$ of the filtrate or sterile water (control) was added to each well. The plates were incubated at $27^{\circ} \mathrm{C}$, and the inhibition zones were measured after clear halos became visible.

Extraction of lipopeptides produced by the antagonists. $\mathrm{HCl}(6 \mathrm{M})$ was used to lower the $\mathrm{pH}$ of the culture filtrates of the four antagonistic bacteria to 2. The filtrates were maintained overnight at $4^{\circ} \mathrm{C}$ and centrifuged to isolate the precipitate, which was then washed twice using diluted $\mathrm{HCl}(\mathrm{pH}$ 2) and extracted twice using methanol (Zhang et al., 2017b). The extract was dried using a rotary vacuum evaporator and resuspended in an equivalent volume of sterile water to detect the biocontrol effects of the extract in controlling the gray mold caused by $B$. cinerea on postharvest fruit.

Efficacy of the antagonists and their culture filtrate and extracts in controlling the gray mold caused by $B$. cinerea on postharvest fruit. To evaluate the efficiency of the four antagonist bacteria, RS-25, MG-4, Z-14, and Pnf4 , and their culture filtrates and extracts in controlling the gray mold on the postharvest fruit of tomato, strawberry, and grape, the in vivo assay reported by Panebianco et al. (2014) and Parafati et al. (2015) was used with slight modifications. Tomato (Lycopersicon esculentum Mill. 'Qianxi'), strawberry (Fragaria $\times$ ananassa Duch. 'Shuangliu'), and grape (Vitis vinifera L. 'Red Globe') fruit were obtained from commercial orchards in Baoding, China. In this study, the tomato, strawberry, and grapefruit did not receive any preharvest fungicide treatment, and only healthy and homogenous fruit were selected. Before treatment and inoculation, the fruits were washed with tap water, superfi- 
cially disinfected for $1 \mathrm{~min}$ in $0.1 \%$ (v/v) sodium hypochlorite, rinsed with SDW, and air-dried at room temperature.

A sterilized needle was used to make artificial wounds $(0.3 \mathrm{~cm}$ in depth $\times 0.5 \mathrm{~cm}$ in width) at equatorial areas of the fruit ( 2 wounds on each fruit). A drop (10 $\mu 1 ; 1 \times 10^{6}$ conidia $/ \mathrm{ml})$ of $B$. cinerea was inoculated in each wound and air-dried for $2 \mathrm{~h}$; then, another drop $\left(10 \mu \mathrm{l} ; 1 \times 10^{8}\right.$ cells $/ \mathrm{ml}$ ) of each bacterium (culture filtrate or extract) was added to each wound. The fruits were placed in plastic packaging cartons ( 5 fruit/carton) and incubated at $25^{\circ} \mathrm{C}$ and $95 \%$ relative humidity for 5 days. Fruits treated with SDW and infected with the pathogen were used as the negative control. Three replicates of 5 fruit each were used per treatment (15 fruit/treatment), and the experiment was repeated thrice. The disease index (DI) and disease reduction (DR) of the gray mold were calculated according to the formulas published by Gong et al. (2017). The degree of disease severity due to inoculation with $B$. cinerea was calculated as follows: $0=$ no lesion; $1=$ a few scattered lesions covering $<2 \%$ of the fruit surface; $2=$ extensive lesions covering $>2 \%$ but $<5 \%$ of the fruit surface; $3=$ extensive lesions covering $>5 \%$ but $<25 \%$ of the fruit surface, and $4=$ extensive lesions covering $>25 \%$ of the fruit surface. The DI was calculated using the following formula:

$$
D I=\left(\sum_{i=0}^{4} n_{i} \times i\right) /\left(4 \times \sum_{i=0}^{4} n_{i}\right) \times 100 \%
$$

Where $i$ is the disease severity (0-4), and $n_{i}$ is the number of fruit with a severity of $i$. The DR was calculated using the following formula: DR $(\%)=100 \times(\mathrm{DI}-B c-\mathrm{DI}$-test $) /$ $\mathrm{DI}-B c$. Where $B c$ is $B$. cinerea.

In vitro production of volatile organic compounds. A dual-culture method was used to assess the efficacy of volatile organic compounds (VOCs) produced by the antagonists in decreasing the growth of B. cinerea (Gao et al., 2017; Grzegorczyk et al., 2017). Twenty-microliter aliquots of the bacterial suspensions $\left(10^{8}\right.$ cells $\left./ \mathrm{ml}\right)$ were seeded on NA plates and incubated at $37^{\circ} \mathrm{C}$ for $24 \mathrm{~h}$. Then, discs (5$\mathrm{mm}$ circular plugs) of actively growing fungal mycelia of $B$. cinerea were placed at the center of Petri dishes with PDA. Each pathogen plate was covered with a plate containing a bacterial culture incubated for $24 \mathrm{~h}$. Three plates were used for each antagonist, and unseeded PDA plates were used as the negative control. The two plates were superimposed with Parafilm around the edges to prevent the leakage of air and incubated at $25^{\circ} \mathrm{C}$. The mycelial diameter was measured after 5 days, and the rate of inhibition of radial mycelial growth was calculated using the equation published by Gao et al. (2018). Three replicates were used for each treatment, and the experiment was repeated thrice. VOCs from the four antagonists were analyzed using solid-phase micro extraction-gas chromatography-mass spectrometry (SPME-GC-MS). For collecting the VOCs, the antagonists were inoculated in NA medium with $25 \mathrm{ml}$ of headspace for 7 days at $28^{\circ} \mathrm{C}$. The NA medium without the antagonistic bacteria was used as the control. DVB/CAR/PDMS fiber (Supelco, Inc., Bellafonte, PA, USA) was applied for headspace SPME of the VOCs at $55^{\circ} \mathrm{C}$ for $40 \mathrm{~min}$. The SPME fiber was immediately inserted into the injection port of the gas chromatography-mass spectrometry (GCMS; Agilent 7820A-5977E, Santa Clara, CA, USA) for thermal desorption at $250^{\circ} \mathrm{C}$ for 5 min with a DB-5MS column $(30 \mathrm{~m} \times 0.25 \mathrm{~mm}$ i.d. $\times 0.25 \mu \mathrm{m}$ film thickness; Agilent J\&W Scientific, Folsom, CA, USA). The initial oven temperature was $60^{\circ} \mathrm{C}$ for $2 \mathrm{~min}$, and it was increased to $100^{\circ} \mathrm{C}$ at a rate of $10^{\circ} \mathrm{C} / \mathrm{min}$, then increased to $180^{\circ} \mathrm{C}$ at a rate of $5^{\circ} \mathrm{C} / \mathrm{min}$, and further increased to $240^{\circ} \mathrm{C}$ at a rate of $10^{\circ} \mathrm{C} / \mathrm{min}$ and held for $5 \mathrm{~min}$. The mass spectrometer was operated in the electron ionization mode $(70 \mathrm{eV})$. The ion source, quadruple, and GC-MS interface temperatures were set at $230^{\circ} \mathrm{C}, 150^{\circ} \mathrm{C}$, and $250^{\circ} \mathrm{C}$, respectively. Mass spectrometry (MS) was performed in the full-scan mode with the $\mathrm{m} / \mathrm{z}$ ranging from 50 to 400 for the analysis of VOCs. The mass spectra data of the volatile compounds were compared with those in the NIST/EPA/NIH Mass Spectrometry Library and Mainlib and/or Replib databases (Gao et al., 2017).

Detection of the in vitro activities of protease, chitinase, and cellulase of the antagonists. The protease activity of the antagonists, indicated by casein degradation, was measured by inoculation on skimmed milk agar with the cross-line method, and the width of each halo was measured as an indicator of the level of protease activity (Yang et al., 2008). The cellulase activity of the antagonists was determined by observing the widths of the clear zones on carboxymethyl cellulose (CMC) agar plates (Ghose, 1987). The chitinase activity of the antagonists was determined by measuring the widths of the clear zones on chitin agar (CA) plates (Roberts and Selitrennikoff, 1988). To measure the activity of the metabolites secreted by the antagonists, four evenly spaced wells ( $7 \mathrm{~mm}$ in diameter) were formed 2.2 $\mathrm{cm}$ from the center of the plate by excision, and a $30-\mu 1$ aliquot of the culture filtrate was added to each well.

Qualitative estimation of siderophore production. The chrome azurol S (CAS) assay was performed to evaluate the effectiveness of the Bacillus antagonists in siderophore 
production (Kurabachew and Wydra, 2013; Schwyn and Neilands, 1987). After 5 days at $28^{\circ} \mathrm{C}$, the siderophoreproducing isolates generated orange zones, and the diameter of the clear zone of these colonies was visually rated. Siderophore production in the culture filtrate was measured as described above.

Biofilm formation by the antagonists. The antagonists were cultured in nutritive broth and shaken to midexponential growth; then, $10 \mu \mathrm{l}$ of the cultured medium was transferred to $1 \mathrm{ml}$ of minimal salts glycerol glutamate (MSgg) medium (Branda et al., 2001) in 24-well polyvinylchloride microtiter plates (Thermo Fisher Scientific, Waltham, MA, USA) and incubated under stationary conditions at $37^{\circ} \mathrm{C}$ for 4 days (Dietel et al., 2013).

Colonization of the wound sites by the antagonists. The ability of the antagonists to colonize the wounds on the grape, strawberry, and tomato fruit was tested using previously described and partially modified procedures (Cirvilleri et al., 2005; Parafati et al., 2015). A sterile needle was used to make artificial wounds (4 wounds/fruit) on superficially sanitized fruit, and $10 \mu \mathrm{l}$ aliquots of the bacterial suspensions $\left(1 \times 10^{6}\right.$ cells $\left./ \mathrm{ml}\right)$ were individually inoculated into the wounds; the fruit were incubated for 5 days under the conditions mentioned previously ( 6 fruit/box). Tissue samples containing the whole wound were cut using a sterile knife after inoculation for $0,24,48,72,96$, and 120 h. The samples were weighed, crushed with a sterilized mortar and pestle, serially diluted, and plated on NA. The bacterial colonies were counted after overnight culture at $37^{\circ} \mathrm{C}$ to calculate the mean colony forming units $\left(\log _{10} \mathrm{cfu}\right)$ on the basis of fresh weight. Three replicates of each fruit type were used per treatment ( 6 fruit per treatment), and the experiment was repeated twice.

Identification of lipopeptides produced by the antagonists. The methanol extracts of the culture filtrates of the four antagonistic bacteria were analyzed using the 5800 matrix-assisted laser desorption ionization-time-of-flight (MALDI-TOF) mass spectrometer (AB SCIEX, Redwood, CA, USA) operated in the positive reflectron mode; $\alpha$-cyano-4-hydroxycinnamic acid was used as the matrix (prepared by dissolving $5 \mathrm{mg}$ in $1 \mathrm{ml}$ of 50:50 acetonitrile: water containing $0.1 \%$ trifluoroacetic acid) (Velho et al., 2011).

Identification of the antagonist isolates. Genomes extracted from the antagonists isolates were analyzed for the $16 \mathrm{~S}$ rRNA gene sequence by using universal primers,
27F (5'-AGAGTTTGATCCTGGCTCAG-3') and 1495R (5'-CTACGGCTACCTTGTTACGA-3'), that amplified a 1,400-bp region of the $16 \mathrm{~S}$ rRNA gene. Phylogenetic analysis was conducted using maximum likelihood in MEGA 5.10 (Tamura et al., 2011). The topology of the phylogenetic tree was evaluated by 1,000 resamplings.

Statistical analysis. The data from the replicates were expressed as mean \pm SD values. SPSS version 17.0 software package (SPSS Inc., Chicago, IL, USA) was used to perform the calculations and comparisons of the treatment means for each experiment. Duncan's test $(P \leq 0.05)$ and one-way analysis of variance were used to determine whether the means differed significantly.

\section{Results}

Activity of the antagonists and their culture filtrates and extracts in controlling the gray mold on the postharvest fruit. The four isolates, RS-25, MG-4, Z-14, and Pnf-4, and their culture filtrates all demonstrated significant antifungal activities against $B$. cinerea. The culture filtrate of RS-25 demonstrated the strongest antifungal activity, whereas that of Pnf-4 was the weakest (Fig. 1). The efficacies of RS-25, MG-4, Z-14, and Pnf-4 and their culture filtrates and extracts against the gray mold caused by $\mathrm{B}$. $\mathrm{Ci}$ nerea on the postharvest tomato, strawberry, and grapefruit are reported in Table 1 and Fig. 2. Generally, Z-14, MG4 , and their culture filtrates and extracts were more active against $B$. cinerea. Pnf-4, RS-25, and their culture filtrates and extracts were relatively ineffective in reducing the DI of the strawberry fruit. The DR of $B$. cinerea was observed to be the highest (82.14) when the strawberry fruits were treated with the cells of Z-14, whereas the culture filtrate of RS-25 was the most ineffective and yielded the lowest DR value (55.08). The DR values of the tomato fruit treated with Z-14, RS-25, and the culture filtrate and extract of

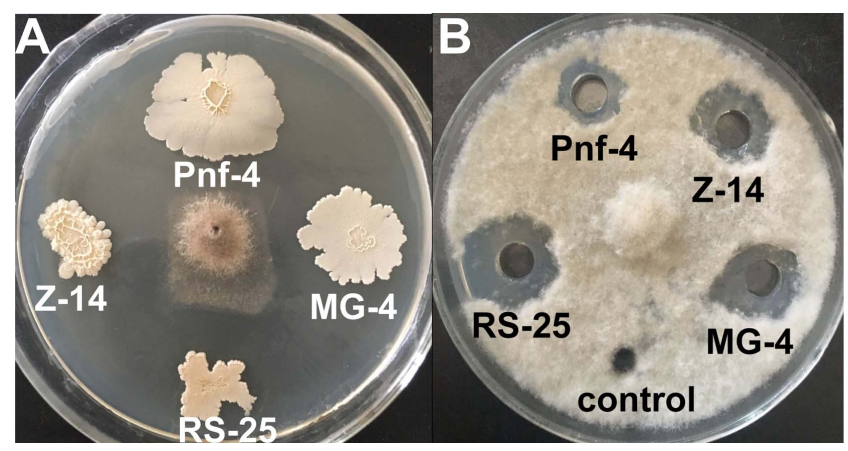

Fig. 1. Antifungal activities of the antagonists (A) and their cultural filtrates (B) against Botrytis cinerea. 
Table 1. Efficacy of the vegetable cells, culture filtrates, and crude extracts of the four antagonists in controlling the gray mold caused by Botrytis cinerea on strawberry, grape, and tomato fruit in a greenhouse

\begin{tabular}{|c|c|c|c|c|c|c|}
\hline \multirow{2}{*}{ Treatment } & \multicolumn{2}{|c|}{ Strawberry } & \multicolumn{2}{|c|}{ Grape } & \multicolumn{2}{|c|}{ Tomato } \\
\hline & DI & DR $(\%)$ & DI & DR $(\%)$ & DI & DR $(\%)$ \\
\hline Pathogen control & $67.03 \pm 4.75 \mathrm{a}$ & - & $70.18 \pm 5.77 \mathrm{a}$ & - & $62.13 \pm 4.61 \mathrm{a}$ & - \\
\hline Vegetable cell of Z-14 & $11.97 \pm 1.47 \mathrm{~d}$ & 82.14 & $40.40 \pm 6.70 \mathrm{~d}$ & 42.43 & $10.80 \pm 2.57 \mathrm{f}$ & 82.62 \\
\hline Culture filtrate of Z-14 & $14.03 \pm 1.43 \mathrm{~d}$ & 79.07 & $61.62 \pm 4.85 b$ & 12.20 & $12.89 \pm 3.35$ ef & 79.25 \\
\hline Crude extract of Z-14 & $19.47 \pm 1.90 \mathrm{c}$ & 70.95 & $52.31 \pm 4.43 \mathrm{c}$ & 25.46 & $15.39 \pm 3.01 \mathrm{def}$ & 75.23 \\
\hline Vegetable cell of Pnf- 4 & $25.19 \pm 2.92 b$ & 62.42 & $21.09 \pm 5.52 \mathrm{e}$ & 69.95 & $19.48 \pm 3.08 \mathrm{cde}$ & 68.65 \\
\hline Culture filtrate of Pnf- 4 & $26.71 \pm 2.53 \mathrm{~b}$ & 60.15 & $11.76 \pm 3.13 \mathrm{f}$ & 83.24 & $27.79 \pm 4.47 \mathrm{~b}$ & 55.27 \\
\hline Crude extract of Pnf- 4 & $27.75 \pm 1.73 b$ & 58.60 & $19.69 \pm 3.81 \mathrm{e}$ & 71.94 & $25.25 \pm 2.58 \mathrm{bc}$ & 59.36 \\
\hline Vegetable cell of MG-4 & $15.42 \pm 3.13 \mathrm{~cd}$ & 77.00 & $10.75 \pm 3.11 \mathrm{f}$ & 84.69 & $20.10 \pm 4.36 \mathrm{~cd}$ & 67.65 \\
\hline Culture filtrate of MG-4 & $13.75 \pm 2.61 \mathrm{~d}$ & 79.49 & $9.63 \pm 2.93 \mathrm{f}$ & 86.28 & $28.56 \pm 4.32 \mathrm{~b}$ & 54.03 \\
\hline Crude extract of MG-4 & $19.42 \pm 1.95 \mathrm{c}$ & 71.03 & $14.58 \pm 2.94 \mathrm{ef}$ & 79.22 & $25.94 \pm 4.04 \mathrm{bc}$ & 58.25 \\
\hline Vegetable cell of RS-25 & $26.41 \pm 1.61 \mathrm{~b}$ & 60.60 & $9.36 \pm 2.87 \mathrm{f}$ & 86.66 & $12.14 \pm 3.58 \mathrm{f}$ & 80.46 \\
\hline Culture filtrate of RS-25 & $30.11 \pm 3.46 \mathrm{~b}$ & 55.08 & $9.26 \pm 2.38 \mathrm{f}$ & 86.81 & $20.32 \pm 4.94 \mathrm{~cd}$ & 67.29 \\
\hline Crude extract of RS-25 & $29.15 \pm 3.55 b$ & 56.51 & $17.06 \pm 2.08 \mathrm{ef}$ & 75.69 & $24.78 \pm 4.39 \mathrm{bc}$ & 60.12 \\
\hline
\end{tabular}

Values are mean \pm SD of three replicates per treatment ( 5 fruit each). As determined by Fisher's protected least significant difference test, the means within a column followed by different letters are significantly different from each other at $P=0.05$.

DI, disease index; DR, disease reduction.

Z-14 were higher $(82.62 \%, 80.46 \%, 79.25 \%$, and $75.23 \%$, respectively) than those of the tomato fruit treated with Pnf-4, MG-4, and the culture filtrate of RS-25 (68.65\%, $67.65 \%$, and $67.29 \%$, respectively). The DR values of the tomato fruit treated with the culture filtrates of Pnf-4 and MG-4 were the lowest (55.27\% and 54.03\%, respectively). The DR values of the grapefruit treated with MG-4 and RS-25 and culture filtrates of Pnf-4, MG-4, and RS-25 were the highest $(84.69 \%, 86.66 \%, 83.24 \%, 86.28 \%$, and $86.81 \%$, respectively), whereas the culture filtrate of Z-14 showed the lowest efficiency in controlling the gray mold $(12.20 \%)$ on grapefruit.

Inhibitory effects of VOCs produced by the antagonists. The variable inhibition efficiency of the VOCs produced by RS-25, MG-4, Z-14, and Pnf-4 against the mycelial growth of $B$. cinerea is shown in Fig. 3. The highest inhibition values were detected for Pnf-4 against $B$. cinerea $(70.71$ $\pm 3.94 \%)$, followed by RS-25 (62.57 $\pm 3.26 \%)$ and MG-4 $(53.44 \pm 2.71 \%)$. In contrast, the VOCs of Z-14 were the most ineffective in reducing the mycelial growth of $B$. cinerea $(24.21 \pm 1.85 \%)$. Based on the headspace SPME-GCMS, 109 potential VOCs produced by RS-25, 93 VOCs by MG-4, 92 by Z-14, and 91 by Pnf- 4 were identified. The main components of the VOCs were ketone, alcohol, aldehyde, olefin, ester, alkane, and phenol, and esters accounted for the highest percentage in the VOCs produced by RS25, MG-4, Z-14, and Pnf-4 (36.80\%, 29.58\%, 30.78\%, and $36.26 \%$, respectively) (Table 2 ).
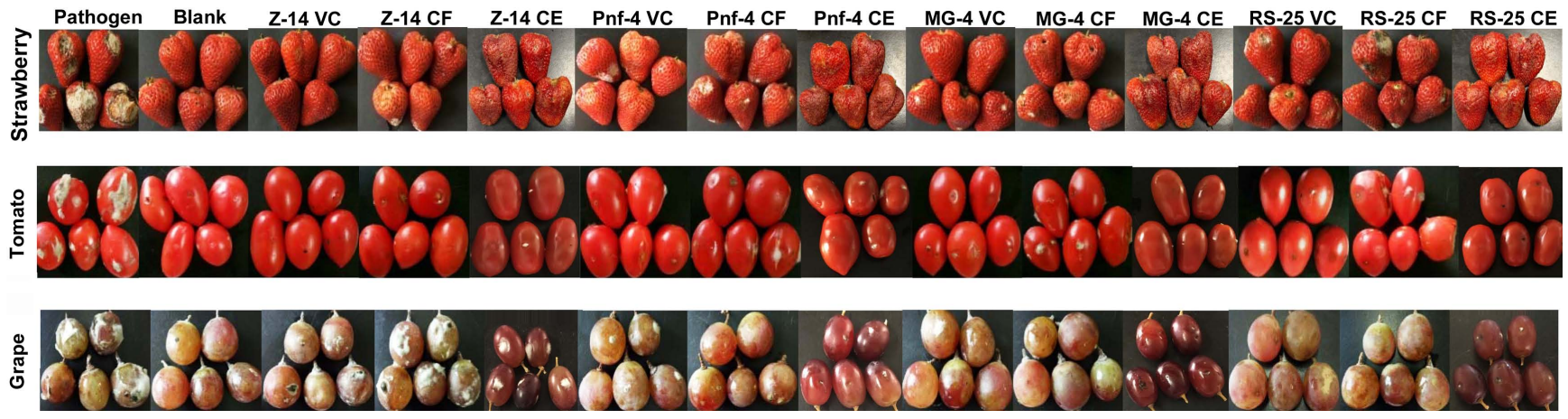

Fig. 2. Efficacy of the vegetable cells, culture filtrates, and crude extracts of the antagonists in controlling the gray mold caused by Botrytis cinerea on postharvest fruit (strawberry, tomato, and grape). VC, vegetable cells; CF, culture filtrate; CE, crude extract. 


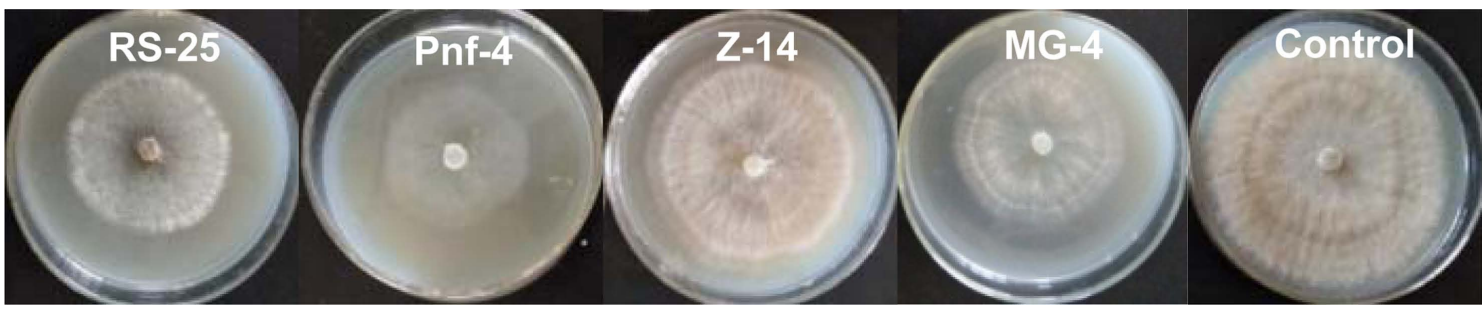

Fig. 3. Evaluation of the efficacy of volatile organic compounds produced by the antagonists in reducing the growth of Botrytis cinerea.

Table 2. Volatile organic compounds (VOCs) produced by the antagonists

\begin{tabular}{|c|c|c|c|c|c|c|c|c|}
\hline \multirow{2}{*}{$\begin{array}{l}\text { Possible } \\
\text { VOCs }\end{array}$} & \multicolumn{2}{|r|}{ RS-25 } & \multicolumn{2}{|r|}{ MG-4 } & \multicolumn{2}{|r|}{ Z-14 } & \multicolumn{2}{|r|}{ Pnf-4 } \\
\hline & No. & $\begin{array}{l}\text { Relative peak area } \\
\qquad(\%)\end{array}$ & No. & $\begin{array}{c}\text { Relative peak area } \\
(\%)\end{array}$ & No. & $\begin{array}{l}\text { Relative peak area } \\
\qquad(\%)\end{array}$ & No. & $\begin{array}{c}\text { Relative peak area } \\
(\%)\end{array}$ \\
\hline Ketone & 35 & 15.08 & 21 & 8.75 & 12 & 3.23 & 19 & 5.27 \\
\hline Alcohol & 5 & 5.97 & 11 & 2.88 & 18 & 8.33 & 5 & 0.95 \\
\hline Aldehyde & 5 & 7.02 & 8 & 1.12 & 6 & 5.37 & 1 & 0.94 \\
\hline Olefin & 5 & 1.41 & 3 & 0.50 & 4 & 0.44 & 3 & 0.09 \\
\hline Ester & 18 & 36.80 & 22 & 29.58 & 19 & 30.78 & 29 & 36.26 \\
\hline Alkane & 30 & 29.71 & 17 & 4.32 & 16 & 8.86 & 30 & 16.24 \\
\hline Phenol & 2 & 4.41 & 3 & 5.57 & 1 & 3.2 & 1 & 0.26 \\
\hline Others & 9 & 14.22 & 8 & 2.47 & 16 & 4.94 & 3 & 0.08 \\
\hline
\end{tabular}

Enzyme activity and siderophore production assays. All the tested Bacillus strains and their culture filtrates were able to hydrolyze $\mathrm{CMC}$, and they produced obvious clear zones in the CMC agar plates. The culture filtrate of Z-14 exhibited the strongest cellulase activity; the diameter of the clear zone was $3.4 \mathrm{~cm}$, whereas those of RS-25, Pnf-4, and MG-4 were $2.4 \mathrm{~cm}, 2.3 \mathrm{~cm}$, and $2.8 \mathrm{~cm}$, respectively (Fig. 4A and B). The four antagonists and their culture filtrates all exhibited potent protease activity, and the hydrolysis zones of RS-25, Z-14, and MG-4 were relatively bigger than that of Pnf-4; this is similar to the protease activity results of the culture filtrates of the antagonists (Fig. 4C and D). The four antagonists and their culture filtrates did not produce clear zones in CA plates, which demonstrated they did not synthesize chitinase. These results are consistent with the findings of Ren et al. (2013), who suggested that Bacillus pumilus JK-SX001 does not secrete chitinase but instead secretes protease and cellulase.

Biofilm formation and colonization of fruit. All four antagonists exhibited the ability to form biofilms on the inert surface of liquid MSgg medium and evolved into whitish aerial structures that appeared to be dry and had a cottonlike texture (Fig. 4G). The population dynamics of RS25, MG-4, Z-14, and Pnf-4 strains on artificially wounded tomato, strawberry, and grapefruit are shown in Fig. 5. The population trends of the antagonists in the wound tissue of tomato fruit, starting from a similar concentration $\left(\log _{10} \mathrm{cfu} / \mathrm{g}\right.$ of tissue $\left.=3.50\right)$, remained relatively stable for a period of $24 \mathrm{~h}$; increased for MG-4, Z-14, and Pnf-4 and a few drops of RS-25 up to $72 \mathrm{~h}$; and were similar $\left(\log _{10}\right.$ $\mathrm{cfu} / \mathrm{g}$ of tissue $=4.30$ ) after $120 \mathrm{~h}$ of incubation (Fig. $5 \mathrm{~A})$.

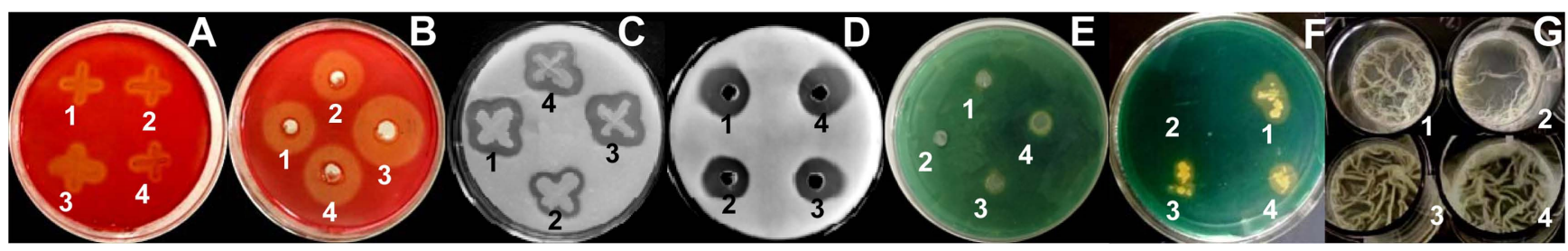

Fig. 4. Detection of the in vitro activities of cellulase, protease, and chitinase; siderophore production; and biofilm formation by the antagonists and their culture filtrates. (A, C) The in vitro activities of cellulase and protease of the antagonists. (B, D) The in vitro activities of cellulase and protease of the culture filtrate. (E, G) Siderophore production and biofilm formation by the antagonists, respectively. (F) Siderophore production by the culture filtrate; 1-4 represent antagonists RS-25, Pnf-4, Z-14, and MG-4, respectively. 

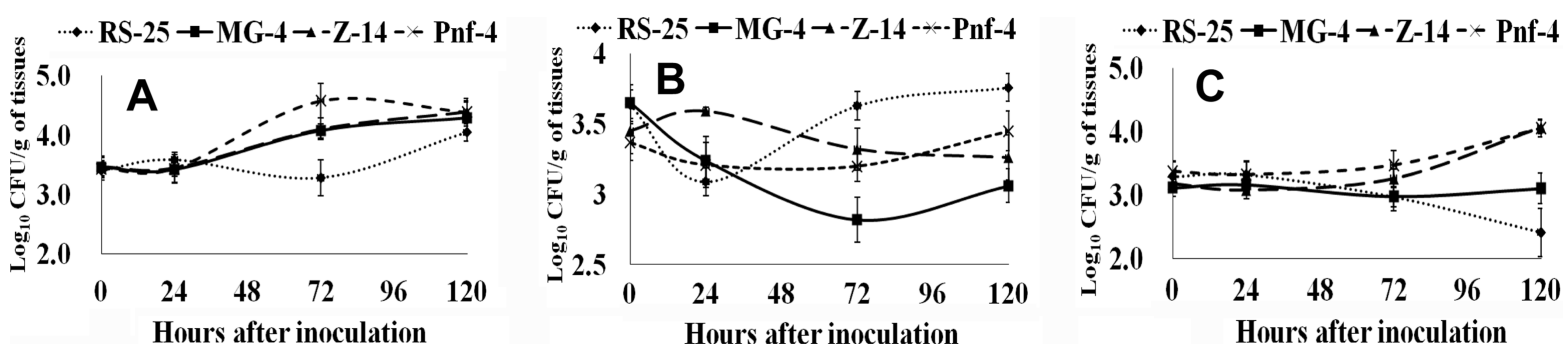

Fig. 5. Population dynamics of the antagonists RS-25, Pnf-4, Z-14, and MG-4 in the wound tissue of tomato fruit (A), strawberry fruit (B), and grapefruit $(\mathrm{C})$. Vertical bars indicate the standard error of the mean. cfu, colony forming unit.

The population trend of the antagonists in the wound tissue of strawberry fruit showed fluctuations to a certain extent during $120 \mathrm{~h}$ after inoculation; RS-25 showed the highest concentration $\left(\log _{10} \mathrm{cfu} / \mathrm{g}\right.$ of tissue $\left.=3.76\right)$, whereas MG-4 showed the lowest concentration $\left(\log _{10} \mathrm{cfu} / \mathrm{g}\right.$ of tissue $=$ 3.06) (Fig. 5B). The population trend of the antagonists in the wound tissue of grapefruit, starting from similar concentrations, ranged from 3.11 ( $\log _{10} \mathrm{cfu} / \mathrm{g}$ of tissue) for MG-4 to 3.37 ( $\log _{10} \mathrm{cfu} / \mathrm{g}$ of tissue) for Pnf-4; growth appeared to be quite stationary up to $24 \mathrm{~h}$, but it showed variations after that period. The population densities of Z-14 and Pnf-4 increased significantly $\left(\log _{10} \mathrm{cfu} / \mathrm{g}\right.$ of tissue $=4.07$ and 4.05 , respectively), whereas the population density of MG-4 remained relatively stable $\left(\log _{10} \mathrm{cfu} / \mathrm{g}\right.$ of tissue $=3.10)$ and that of RS-25 showed a notable decline $\left(\log _{10} \mathrm{cfu} / \mathrm{g}\right.$ of tissue $\left.=2.41\right)($ Fig. $5 \mathrm{C})$. The results prove that the population densities of the four antagonists in the three types of fruit showed different colonization capacities. The colonization abilities of the antagonists were similar in the wounds of the tomato fruit but different in those of the strawberry and grapefruit. The colonization ability of RS-25 was the strongest in the wounds of the strawberry fruit, but weakest in those of the grapefruit.

Identification of lipopeptides produced by the antagonists. MALDI-TOF mass spectrometry was used to analyze the lipopeptide antibiotics produced by the antagonists. The mass spectra of the crude extract from RS-25 revealed two major clusters with peaks at $\mathrm{m} / \mathrm{z} 1,016.69-1,074.70 \mathrm{Da}$, which correspond to the isoforms of surfactin $\mathrm{B}$, and peaks
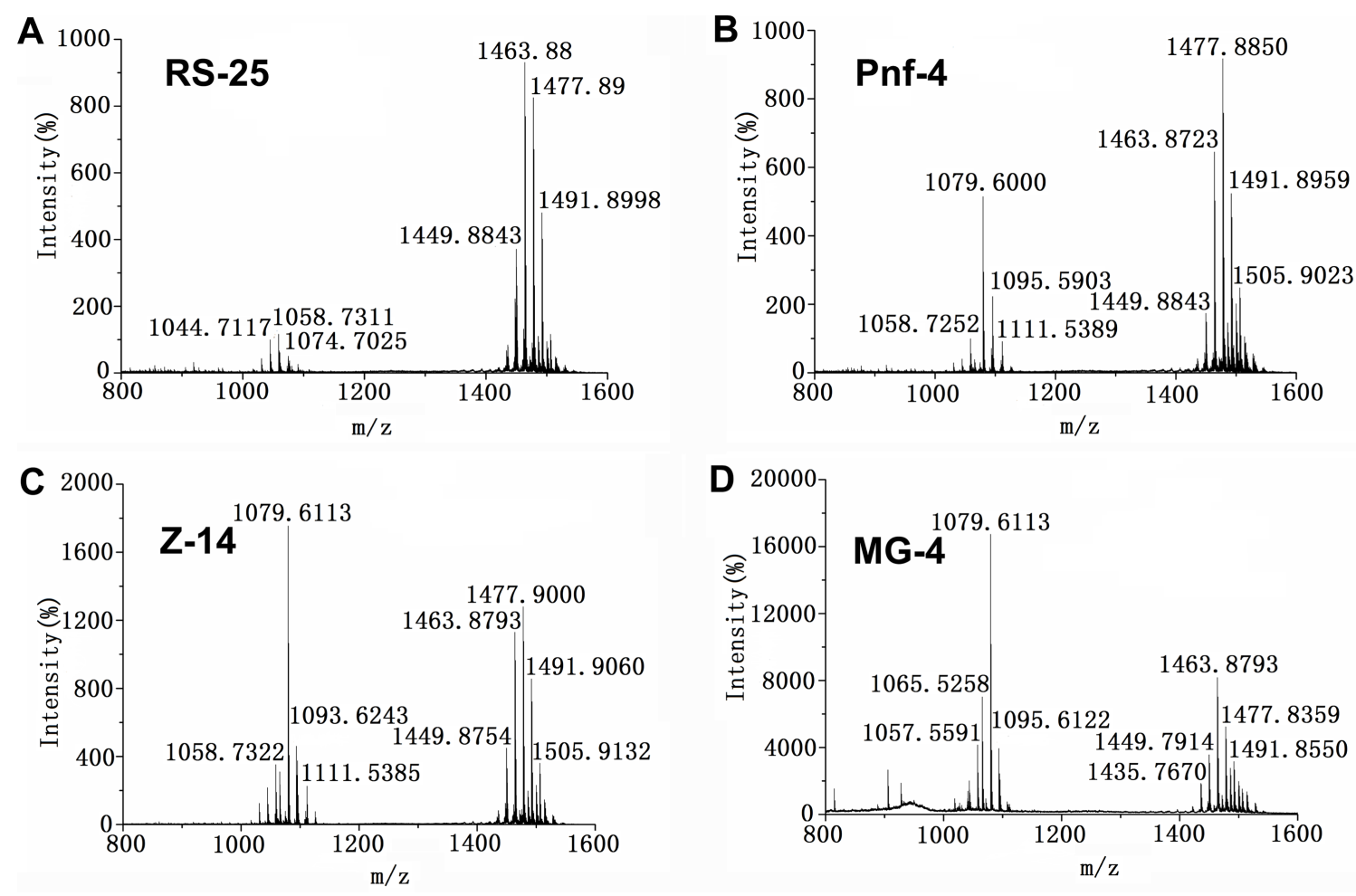

Fig. 6. (A-D) Mass spectroscopy analysis of the lipopeptides produced by the antagonists. 


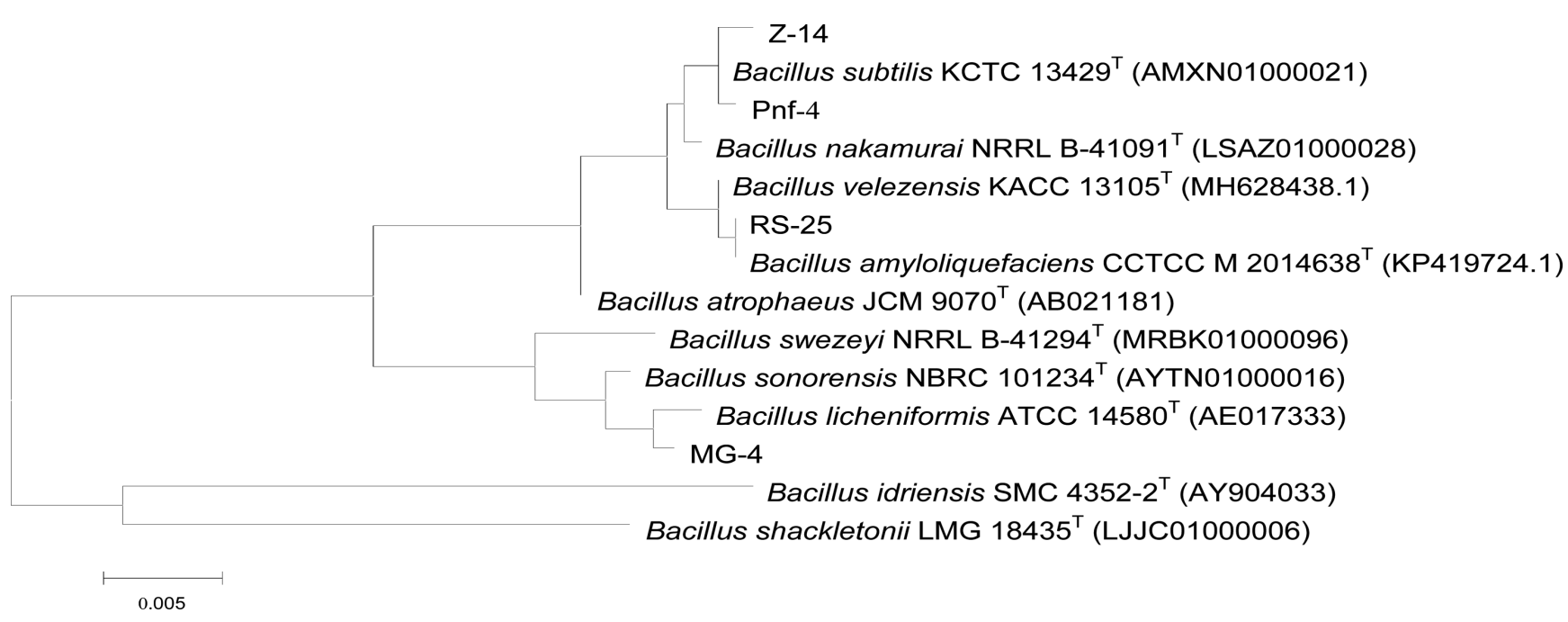

Fig. 7. Unrooted phylogenetic tree based on the $16 \mathrm{~S}$ rRNA sequences of the antagonists.

at $\mathrm{m} / \mathrm{z} 1,433.88-1,529.88 \mathrm{Da}$, which correspond to the isoforms of fengycin (Fig. 6A). The mass spectra of the crude extract from Pnf-4 revealed three major clusters with peaks at $\mathrm{m} / \mathrm{z}$ 1,030.70-1,074.72 $\mathrm{Da}$, which correspond to surfactin $\mathrm{B}$, peaks at $\mathrm{m} / \mathrm{z} 1,079.62-1,125.57 \mathrm{Da}$, which correspond to iturin $\mathrm{A}$, and peaks at $\mathrm{m} / \mathrm{z}$ 1,435.87-1,543.88 Da, which correspond to fengycin (Fig. 6B). Surfactin B, iturin A, and fengycin were detected from Z-14 (Fig. 6C), and iturin A and fengycin, from MG-4 (Fig. 6D).

Identification of the antagonists. When compared with the GenBank database, the 16S rRNA sequences of the strains were matched to those of Bacillus spp. The constructed unrooted phylogenetic tree revealed that antagonist Pnf-12 was most similar to B. subtilis, according to the alignment results. Antagonist RS-25 was identified as Bacillus amyloliquefaciens; MG-4, Bacillus licheniformis; and Z-14, B. subtilis (Fig. 7).

\section{Discussion}

Previous studies have shown that biological control, such as the application of antagonist microorganisms or their secondary metabolites, is a promising method for decreasing the decay of harvested fruit (Li et al., 2016; Wu et al., 2017). Postharvest treatments with antagonist microorganisms such as Bacillus (Gao et al., 2017; Zhang et al., 2013), Clonostachys rosea (Gong et al., 2017), and yeast strains (Parafati et al., 2015) have been reported to suppress the development of $B$. cinerea and decay of harvested fruit.

In this study, the main biocontrol modes of action of the four Bacillus antagonists against the in vitro growth of $B$. cinerea, such as biofilm formation; competition for iron; and production of VOCs, cell-wall-degrading enzymes, and lipopeptide antibiotics, were evaluated on the basis of the mechanisms that play a significant role in the biocontrol activities of antagonistic bacteria. Secondary metabolites play key roles in the antifungal activities of antagonistic bacteria; however, the production of these antagonistic metabolites is greatly affected by the environment (Zhang et al., 2017a). The direct use of antimicrobial substances synthesized by microorganisms as the basis of microbial pesticides can overcome such limitations (Kilani-Feki et al., 2016). Antifungal substances readily decompose and do not pollute the environment (Gu et al., 2017). No significant differences in biocontrol activities were observed between the antagonists and their culture filtrates against the gray mold on the strawberry fruit; however, the crude extract of Z-14 showed lower efficiency than the cells and culture filtrate. The biocontrol efficiency of Z-14, including that of its culture filtrate and extract, was the lowest of the four antagonists on the grapefruit, but the extract of Z-14 showed higher efficiency than the vegetable cells. The vegetable cells of the antagonists demonstrated higher biocontrol activities against the gray mold on the tomato fruit than their culture filtrates and extracts (Table 1, Fig. 2). The different biocontrol activities of the antagonists in the three fruits showed that the effects of the antagonists were influenced by the host fruit.

There is limited information on the antifungal activities of VOCs from microorganisms. Naturally occurring VOCs of endophytic bacteria are regarded as sources of new antifungal agents that are safe for humans and the environment and do not have a harmful influence on the host plants 
(Gao et al., 2017). Microbial VOCs inhibit the growth of pathogenic fungi; improve plant growth (Park et al., 2015); mediate relationships, interactions, and communications between organisms (Cernava et al., 2015); identify bacterial species; and induce systemic resistance in plants (Zamioudis et al., 2015). GC-MS has revealed that 29 unique VOCs produced by Bacillus velezensis ZSY-1 isolated from Chinese catalpa exhibit significant antifungal activity against plant pathogenic fungi (Gao et al., 2017). VOCs may act in both direct and indirect modes during the interaction between bacterial agents and fungal pathogens (Zhang et al., 2013). The antifungal activity of the VOCs of Z-14 was the weakest of the four antagonists; however, Z-14 displayed the strongest biocontrol effect on the strawberry and tomato fruit. This may indicate that the production of VOCs is not the main mechanism exhibited by Bacillus strains against plant pathogenic fungi.

Aureobasidium pullulans (three strains) and Wickerhamomyces anomalus (four strains) have been tested for extracellular lytic enzyme activity, and all seven strains showed $\beta$-1,3-glucanase and protease activities but no chitinase activity (Parafati et al., 2015). Physical damage of the hypha prevents its penetration into the host cell wall. Loss of turgidity and tearing of the pathogen hyphae may both be attributable to cellulase and protease activities. These metabolites may be involved in the control of phytopathogenic fungi through mycoparasitism, which is characterized by colonization of pathogen hyphae (Grzegorczyk et al., 2017). RS-25, Z-14, and MG-4 grew on CAS agar; an orange halo was formed around the colonies, except those of Pnf-4; this is consistent with the results of the culture filtrates of these antagonists (Fig. 3E and F). Generally, siderophores are produced by microorganisms to bind $\mathrm{Fe}^{3+}$ from the environment, transport it to the microbial cell, and make it available for growth (Leong, 1996). Therefore, competition for iron may also be a possible mechanism for controlling phytopathogens (Xue et al., 2013).

Generally, biofilm formation is regarded as a major mechanism of antagonists against plant pathogenic fungi, as biofilms act as physical and chemical barriers (Díaz Herrera et al., 2016; Dietel et al., 2013). Haggag and Timmusk (2008) showed that Paenibacillus polymyxa strains produced biofilms to control the crown root rot disease, which is caused by Aspergillus niger. A previous study has shown that $W$. anomalus and Metschnikowia pulcherrima strains were able to adhere to polystyrene plates and maintain a high film-forming capacity after $48 \mathrm{~h}$ and $72 \mathrm{~h}$ of incubation, even after repeated washes (Parafati et al., 2015).

The presence of a high number of antagonists in the wounded tissues would protect the plants or fruit from pathogens because tissue colonization by biocontrol agents is critical for the effective control of phytopathogens (Zeriouh et al., 2014). The antagonists can successfully compete with the phytopathogens for the niches and nutrients, such as organic compounds, that are essential for the reactivation of propagules and/or subsequent proliferation and colonization of tissues (Budiharjo et al., 2014). The colonization capacities of antagonists in tissues may have a key role in disease suppression, even if competition or antibiosis occurs between the antagonists and pathogens (Huang et al., 2013). The four antagonists showed similar colonization abilities but different biocontrol effects against the gray mold in the tomato fruit, which indicates that secondary metabolites may play a major role in the control activity (Table 1, Figs. 2 and 5A). The colonization abilities and control activities of the antagonists did not have a direct correlation in the strawberry and grapefruit. RS-25 displayed the strongest colonization ability and lowest biocontrol effect in the strawberry fruit (Table 1, Figs. 2 and 5B), but the strongest biocontrol effect and lowest colonization ability in the grapefruit (Table 1, Figs. 2 and 5C).

Lipopeptide antibiotics, such as iturins, fengycins, and surfactins, are an important class of antifungal substances synthesized by Bacillus (Moyne et al., 2004). Lipopeptide antibiotics have direct or indirect inhibitory effects on fungal plant pathogens, but they are not toxic to the plant itself (Ongena and Jacques, 2008; Zhang et al., 2017b). MALDITOF mass spectrometry can be easily and conveniently used for component identification (Sandrin et al., 2013; Xie et al., 2012). This study showed that MALDI-TOF mass spectrometry could become a new, sensitive, and rapid technique for detecting metabolites. MALDI-TOF mass spectrometry has been used to show that B. amyloliquefaciens FZB42 promotes plant growth, suppresses plant pathogenic organisms in the rhizosphere of plants, and synthetizes and excretes bacillomycin D, fengycin, and surfactin (Koumoutsi et al., 2004). Three types of lipopeptides, surfactin A, iturin A, and fengycin, produced by B. subtilis CMB32 isolated from the soil by Kim et al. (2010) have been reported for their potential to control the anthracnose disease caused by Colletotrichum gloeosporioides. Lipopeptide antibiotics are relatively stable in nature and resistant to acids and bases, which ensure that the lipopeptide antibiotics can exert antagonistic effects over a long period (Fan et al., 2017; Guo et al., 2014). Iturins and fengycins exhibit a wide range of strong inhibitory activities against fungal plant pathogens. Romero et al. (2007) concluded that the iturin and fengycin families of lipopeptides have a major role in the antagonism of B. subtilis towards Podosphaera fusca, which is the main causal agent of cucurbit 
powdery mildew in Spain. Fengycin-type lipopeptides produced by $B$. subtilis NCD-2 were the main antifungal compounds that restricted the population of Rhizoctonia solani in the cotton rhizosphere and suppressed cotton dampingoff disease (Guo et al., 2014).

In summary, the cells of Z-14, culture filtrate of RS-25, and cells of Z-14 showed the strongest biocontrol activity against the gray mold on the postharvest strawberry, grape, and tomato fruit, respectively. Biofilm formation; strong colonization ability in fruit tissues; and subsequent production of VOCs, cellulase and protease, siderophores, and lipopeptide antibiotics may be the main modes of action of the antagonist bacteria against $B$. cinerea on the postharvest fruit. This study provides theoretical support and material basis for developing agents against the gray mold caused by $B$. cinerea on postharvest fruit.

\section{Acknowledgments}

We would like to thank the native English-speaking scientists of Elixigen Company (Huntington Beach, California) for editing our manuscript. This work was supported by the Hebei Provincial Natural Science Foundation of China (grant number C2014204027).

\section{References}

Abdallah, R. A. B., Mokni-Tlili, S., Nefzi, A., Jabnoun-Khiareddine, H. and Daami-Remadi, M. 2016. Biocontrol of Fusarium wilt and growth promotion of tomato plants using endophytic bacteria isolated from Nicotiana glauca organs. Biol. Control 97:80-88.

Bautista-Rosales, P. U., Calderon-Santoya, M., Servín-Villegas, R., Ochoa-Álvarez, N. A. and Ragazzo-Sánchez, J. A. 2013. Action mechanisms of the yeast Meyerozyma caribbica for the control of the phytopathogen Colletotrichum gloesporioides in mangoes. Biol. Control 65:293-301.

Branda, S. S., González-Pastor, J. E., Ben-Yehuda, S., Losick, R. and Kolter, R. 2001. Fruiting body formation by Bacillus subtilis. Proc. Natl. Acad. Sci. U. S. A. 98:11621-11626.

Budiharjo, A., Chowdhury, S. P., Dietel, K., Beator, B., Dolgova, O., Fan, B., Bleiss, W., Ziegler, J., Schmid, M., Hartmann, A. and Borriss, R. 2014. Transposon mutagenesis of the plantassociated Bacillus amyloliquefaciens ssp. plantarum FZB42 revealed that the $n f r A$ and $R B A M 17410$ genes are involved in plant-microbe-interactions. PLoS ONE 9:e98267.

Cernava, T., Aschenbrenner, I. A., Grube, M., Liebminger, S. and Berg, G. 2015. A novel assay for the detection of bioactive volatiles evaluated by screening of lichen associated bacteria. Front. Microbiol. 6:398.

Cirvilleri, G., Bonaccorsi, A., Scuderi, G. and Scortichini, M. 2005. Potential biological control activity and genetic diver- sity of Pseudomonas syringae pv. syringae strains. J. Phytopathol. 153:654-666.

Conway, W. S., Leverentz, B., Janisiewicz, W. J., Saftner, R. A. and Camp, M. J. 2005. Improving biocontrol using antagonist mixtures with heat and/or sodium bicarbonate to control postharvest decay of apple fruit. Postharvest Biol. Technol. 36:235-244.

Dean, R., Van Kan, J. A. L., Pretorius, Z. A., Hammond-Kosack, K. E., Di Pietro, A., Spanu, P. D., Rudd, J. J., Dickman, M., Kahmann, R., Ellis, J. and Foster, G. D. 2012. The Top 10 fungal pathogens in molecular plant pathology. Mol. Plant Pathol. 13:414-430.

Derckel, J.-P., Baillieul, F., Manteau, S., Audran, J.-C., Haye, B., Lambert, B. and Legendre, L. 1999. Differential induction of grapevine defences by two strains of Botrytis cinerea. Phytopathology 89:197-203.

Díaz Herrera, S., Grossi, C., Zawoznik, M. and Groppa, M. D. 2016. Wheat seeds harbour bacterial endophytes with potential as plant growth promoters and biocontrol agents of $\mathrm{Fu}$ sarium graminearum. Microbiol. Res. 186-187:37-43.

Dietel, K., Beator, B., Budiharjo, A., Fan, B. and Borriss, R. 2013. Bacterial traits involved in colonization of Arabidopsis thaliana roots by Bacillus amyloliquefaciens FZB42. Plant Pathol. J. 29:59-66.

Droby, S. 2006. Improving quality and safety of fresh fruits and vegetables after harvest by the use of biocontrol agents and natural materials. Acta Hortic. 709:45-51.

Fan, H., Ru, J., Zhang, Y., Wang, Q. and Li, Y. 2017. Fengycin produced by Bacillus subtilis 9407 plays a major role in the biocontrol of apple ring rot disease. Microbiol. Res. 199:8997.

Fekete, É., Fekete, E., Irinyi, L., Karaffa, L., Árnyasi, M., Asadollahi, M. and Sándor, E. 2012. Genetic diversity of a Botrytis cinerea cryptic species complex in Hungary. Microbiol. Res. 167:283-291.

Gao, H., Li, P., Xu, X., Zeng, Q. and Guan, W. 2018. Research on volatile organic compounds from Bacillus subtilis CF3: biocontrol effects on fruit fungal pathogens and dynamic changes during fermentation. Front. Microbiol. 9:456.

Gao, Z., Zhang, B., Liu, H., Han, J. and Zhang, Y. 2017. Identification of endophytic Bacillus velezensis ZSY-1 strain and antifungal activity of its volatile compounds against Alternaria solani and Botrytis cinerea. Biol. Control 105:27-39.

Ghose, T. K. 1987. Measurement of cellulase activities. Pure Appl. Chem. 59:257-268.

Gong, C., Liu, Y., Liu, S.-Y., Cheng, M.-Z., Zhang, Y., Wang, R.H., Chen, H.-Y., Li, J.-F., Chen, X.-L. and Wang, A.-X. 2017. Analysis of Clonostachys rosea-induced resistance to grey mould disease and identification of the key proteins induced in tomato fruit. Postharvest Biol. Technol. 123:83-93.

Grzegorczyk, M., Żarowska, B., Restuccia, C. and Cirvilleri, G. 2017. Postharvest biocontrol ability of killer yeasts against Monilinia fructigena and Monilinia fructicola on stone fruit. Food Microbiol. 61:93-101. 
Gu, K.-B., Zhang, D.-J., Guan, C., Xu, J.-H., Li, S.-I., Shen, G.-M., Luo, Y.-C. and Li, Y.-G. 2017. Safe antifungal lipopeptides derived from Bacillus marinus B-9987 against grey mold caused by Botrytis cinerea. J. Integr. Agric. 16:1999-2008.

Guo, Q., Dong, W., Li, S., Lu, X., Wang, P., Zhang, X., Wang, Y. and Ma, P. 2014. Fengycin produced by Bacillus subtilis NCD-2 plays a major role in biocontrol of cotton seedling damping-off disease. Microbiol. Res. 169:533-540.

Haggag, W. M. and Timmusk, S. 2008. Colonization of peanut roots by biofilm-forming Paenibacillus polymyxa initiates biocontrol against crown rot disease. J. Appl. Microbiol. 104:961-969.

Huang, J., Wei, Z., Tan, S., Mei, X., Yin, S., Shen, Q. and Xu, Y. 2013. The rhizosphere soil of diseased tomato plants as a source for novel microorganisms to control bacterial wilt. Appl. Soil Ecol. 72:79-84.

Kilani-Feki, O., Khedher, S. B., Dammak, M., Kamoun, A., Jabnoun-Khiareddine, H., Daami-Remadi, M. and Tounsi, S. 2016. Improvement of antifungal metabolites production by Bacillus subtilis V26 for biocontrol of tomato postharvest disease. Biol. Control 95:73-82.

Kim, P. I., Ryu, J., Kim, Y. H. and Chi, Y.-T. 2010. Production of biosurfactant lipopeptides Iturin A, Fengycin, and Surfactin A from Bacillus subtilis CMB32 for control of Colletotrichum gloeosporioides. J. Microbiol. Biotechnol. 20:138-145.

Koumoutsi, A., Chen, X.-H., Henne, A., Liesegang, H., Hitzeroth, G., Franke, P., Vater, J. and Borriss, R. 2004. Structural and functional characterization of gene clusters directing nonribosomal synthesis of bioactive cyclic lipopeptides in Bacillus amyloliquefaciens strain FZB42. J. Bacteriol. 186:10841096.

Kurabachew, H. and Wydra, K. 2013. Characterization of plant growth promoting rhizobacteria and their potential as bioprotectant against tomato bacterial wilt caused by Ralstonia solanacearum. Biol. Control 67:75-83.

Leong, J. 1996. Siderophores: their biochemistry and possible role in the biocontrol of plant pathogens. Annu. Rev. Phytopathol. 24:187-209.

Li, W., Zhang, H., Li, P., Apaliya, M. T., Yang, Q., Peng, Y. and Zhang, X. 2016. Biocontrol of postharvest green mold of oranges by Hanseniaspora uvarum Y3 in combination with phosphatidylcholine. Biol. Control 103:30-38.

Mari, M., Martini, C., Guidarelli, M. and Neri, F. 2012. Postharvest biocontrol of Monilinia laxa, Monilinia fructicola and Monilinia fructigena on stone fruit by two Auerobasidium pullulans strains. Biol. Control 60:132-140.

Mirzaei, S., Goltapeh, E. M., Shams-Bakhsh, M., Safaie, N. and Chaichi, M. 2009. Genetic and phenotypic diversity among Botrytis cinerea isolates in Iran. J. Phytopathol. 157:474-482.

Moyne, A.-L., Cleveland, T. E. and Tuzun, S. 2004. Molecular characterization and analysis of the operon encoding the antifugal lipopeptide bacillomycin D. FEMS Microbiol. Lett. 234:43-49.

Nalinia, S. and Parthasarathi, R. 2014. Production and charac- terization of rhamnolipids produced by Serratia rubidaea SNAU02 under solid-state fermentation and its application as biocontrol agent. Bioresour. Technol. 173:231-238.

Ongena, M. and Jacques P. 2008. Bacillus lipopeptides: versatile weapons for plant disease biocontrol. Trends Microbiol. 16:115-125.

Panebianco, S., Vitale, A., Platania, C., Restuccia, C., Polizzi, G. and Cirvilleri, G. 2014. Postharvest efficacy of resistance inducers for the control of green mold on important Sicilian citrus varieties. J. Plant Dis. Prot. 121:177-183.

Park, Y.-S., Dutta, S., Ann, M., Raaijmakers, J. M. and Park, K. 2015. Promotion of plant growth by Pseudomonas fluorescens strain SS101 via novel volatile organic compounds. Biochem. Biophys. Res. Commun. 461:361-365.

Parafati, L., Vitale, A., Restuccia, C. and Cirvilleri, G. 2015. Biocontrol ability and action mechanism of food-isolated yeast strains against Botrytis cinerea causing post-harvest bunch rot of table grape. Food Microbiol. 47:85-92.

Platania, C., Restuccia, C., Muccilli, S. and Cirvilleri, G. 2012. Efficacy of killer yeast in the biological control of Penicillium digitatum on Tarocco orange fruits (Citrus sinensis). Food Microbiol. 30:219-225.

Posada, L. F., Ramírez, M., Ochoa-Gómez, N., Cuellar-Gaviria, T. Z., Argel-Roldan, L. E., Ramírez, C. A. and Villegas-Escobar, V. 2016. Bioprospecting of aerobic endospore-forming bacteria with biotechnological potential for growth promotion of banana plants. Sci. Hortic. 212:81-90.

Pretorius, D., van Rooyen, J. and Clarke, K. G. 2015. Enhanced production of antifungal lipopeptides by Bacillus amyloliquefaciens for biocontrol of postharvest disease. New Biotechnol. 32:243-252.

Ren, J.-H., Li, H., Wang, Y.-F., Ye, J.-R., Yan, A.-Q. and Wu, X.-Q. 2013. Biocontrol potential of an endophytic Bacillus pumilus JK-SX001 against poplar canker. Biol. Control 67:421-430.

Roberts, W. K. and Selitrennikoff, C. P. 1988. Plant and bacterial chitinases differ in antifungal activity. J. Gen. Microbiol. 134:169-176.

Romero, D., de Vicente, A., Rakotoaly, R. H., Dufour, S. E., Veening, J.-W., Arrebola, E., Cazorla, F. M., Kuipers, O. P., Paquot, M. and Pérez-García, A. 2007. The iturin and fengycin families of lipopeptides are key factors in antagonism of Bacillus subtilis toward Podosphaera fusca. Mol. PlantMicrobe Interact. 20:430-440.

Sandrin, T. R., Goldstein, J. E. and Schumaker, S. 2013. MALDI TOF MS profiling of bacteria at the strain level: a review. Mass Spectrom. Rev. 32:188-217.

Schnaubelt, K. 2005. Essential oil therapy according to traditional Chinese medical concepts. Int. J. Aromather. 15:98-105.

Schwyn, B. and Neilands, J. B. 1987. Universal chemical assay for the detection and determination of siderophores. Anal. Biochem. 160:47-56.

Soylu, E. M., Kurt, Ş. and Soylu, S. 2010. In vitro and in vivo antifungal activities of the essential oils of various plants against tomato grey mould disease agent Botrytis cinerea. Int. 
J. Food Microbiol. 143:183-189.

Stein, T. 2005. Bacillus subtilis antibiotics: structures, syntheses and specific functions. Mol. Microbiol. 56:845-857.

Tamura, K., Peterson, D., Peterson, N., Stecher, G., Nei, M. and Kumar, S. 2011. MEGA 5: molecular evolutionary genetics analysis using maximum likelihood, evolutionary distance, and maximum parsimony methods. Mol. Biol. Evol. 28:27312739.

Velho, R. V., Medina, L. F. C., Segalin, J. and Brandelli, A. 2011. Production of lipopeptides among Bacillus strains showing growth inhibition of phytopathogenic fungi. Folia Microbiol. 56:297.

Williamson, B., Tudzynski, B., Tudzynski, P. and Van Kan, J. A. L. 2007. Botrytis cinerea: the cause of grey mould disease. Mol. Plant Pathol. 8:561-580.

Wu, Y., Lin, H., Lin, Y., Shi, J., Xue, S., Hung, Y.-C., Chen, Y. and Wang, H. 2017. Effects of biocontrol bacteria Bacillus amyloliquefaciens LY-1 culture broth on quality attributes and storability of harvested litchi fruit. Postharvest Biol. Technol. 132:81-87.

Xie, Y. L., Xu, Z. W., Ma, L. Z. and Gao, X. W. 2012. Molecular identification of Bacillus strains isolated from rhizosphere of Betula platyphylla in Qinghai Beishan timberland and its antagonistic activity analysis. Acta Phytophylacica Sin. 39:246252.

Xue, L., Xue, Q., Chen, Q., Lin, C., Shen, G. and Zhao, J. 2013. Isolation and evaluation of rhizosphere actinomycetes with potential application for biocontrol of Verticillium wilt of cotton. Crop Prot. 43:231-240.
Yang, J.-H., Liu, H.-X., Zhu, G.-M., Pan, Y.-L., Xu, L.-P. and Guo, J.-H. 2008. Diversity analysis of antagonists from riceassociated bacteria and their application in biocontrol of rice diseases. J. Appl. Microbiol. 104:91-104.

Zamioudis, C., Korteland, J., Van Pelt, J. A., van Hamersveld, M., Dombrowski, N., Bai, Y., Hanson, J., Van Verk, M. C., Ling, H.-Q., Schulze-Lefert, P. and Pieterse, C. M. J. 2015. Rhizobacterial volatiles and photosynthesis-related signals coordinate MYB72 expression in Arabidopsis roots during onset of induced systemic resistance and iron-deficiency responses. Plant J. 84:309-322.

Zeriouh, H., de Vicente, A., Pérez-García, A. and Romero, D. 2014. Surfactin triggers biofilm formation of Bacillus subtilis in melon phylloplane and contributes to the biocontrol activity. Environ. Microbiol. 16:2196-2211.

Zhang, D., Gao, T., Li, H., Lei, B. and Zhu, B. 2017a. Identification of antifungal substances secreted by Bacillus subtilis Z-14 that suppress Gaeumannomyces graminis var. tritici. Biocontrol Sci. Technol. 27:237-251.

Zhang, D. D., Guo, X. J., Wang, Y. J., Gao, T. G. and Zhu, B. C. 2017 b. Novel screening strategy reveals a potent Bacillus antagonist capable of mitigating wheat take-all disease caused by Gaeumannomyces graminis var. tritici. Lett. Appl. Microbiol. 65:512-519.

Zhang, X., Li, B., Wang, Y., Guo, Q., Lu, X., Li, S. and Ma, P. 2013. Lipopeptides, a novel protein, and volatile compounds contribute to the antifungal activity of the biocontrol agent Bacillus atrophaeus CAB-1. Appl. Microbiol. Biotechnol. 97:9525-9534. 